\title{
CORRELATION BETWEEN SYMPTOMS AND SAGITTAL ALIGNMENT PARAMETERS IN PATIENTS WITH LUMBAR CANAL STENOSIS: A CASE-CONTROL STUDY
}

\author{
CORRELAÇÃO ENTRE OS SINTOMAS E OS PARÂMETROS DE ALINHAMENTO SAGITAL EM \\ PACIENTES COM ESTENOSE DO CANAL LOMBAR: ESTUDO DE CASO-CONTROLE
}

\author{
CORRELACIÓN ENTRE SÍNTOMAS Y PARÁMETROS DE ALINEACIÓN SAGITAL \\ EN PACIENTES CON ESTENOSIS DEL CANAL LUMBAR: UN ESTUDIO \\ DE CONTROL DE CASOS
}

Paulo Tadeu Mala Cavali ${ }^{1}$, Wagner PasqualinI ${ }^{1}$, Marcelo Ítalo Risso ${ }^{2}$, Guilherme Rebechi Zuiani ${ }^{2}$, Joäo Batista de Miranda ${ }^{3}$

\begin{abstract}
Objective: To examine the relationship between sagittal balance parameters and different symptoms of spinal disease in patients with lumbar canal stenosis (LCS) and controls. Methods: In this prospective, diagnostic, case-control study, we included all patients consecutively admitted to a public teaching hospital for surgical treatment of LCS between July 2010 and October 2011, aged more than 40 years, with back pain plus radiculopathy or neurogenic claudication, and controls without LCS. Magnetic resonance and x-rays allowed the measurement of sagittal axis parameters. Clinical data, the Oswestry Disability Index and the visual analogue scale of pain were assessed. Results: 23 patients were in the Stenosis group, and 17 were controls. The Stenosis group presented lower values of total lumbopelvic lordosis and regional lordosis L1, L2 and L3. In LCS patients and back pain, total lumbopelvic and regional lordosis at L1, L2 and L3 were smaller. Those with stenosis and radiculopathy had higher values of pelvic tilt and lower total lumbopelvic lordosis and regional lordosis in $L 1$ and L2. In patients with claudication, regional lumbopelvic lordosis in L1 and L2 and the T9 sagittal offset were smaller. All patients with pain had higher values of thoracic kyphosis, regional lumbopelvic lordosis in L1, lower values for pelvic tilt, sagittal T1 offset, sacro-femoral distance and overhang compared to patients without pain. Conclusions: This study shows significant correlations between symptoms and sagittal axis parameters between patients with and without spinal canal stenosis and also in subgroups of the patients with stenosis with different complaints.
\end{abstract}

Keywords: Spine; Spinal stenosis; Back pain; Low back pain; Magnetic resonance imaging.

RESUMO

Objetivos: Examinar a relação entre parâmetros do alinhamento sagital e diferentes sintomas de doenças da coluna em pacientes com estenose do canal lombar (ECL) e controles. Métodos: Neste estudo prospectivo, diagnóstico, de caso-controle, foram incluídos todos os pacientes consecutivamente internados num hospital universitário público para tratamento da estenose de canal lombar (ECL) entre julho de 2010 e outubro de 2011, com mais de 40 anos e dor lombar mais radiculopatia ou claudicação neurogênica e controle sem ECL. Ressonância magnética e radiografias permitiram as medidas dos parâmetros do eixo sagital. Foram analisados dados clínicos, índice de disfunção de Oswestry e escala visual analógica de dor. Resultados: Vinte e três pacientes estavam no grupo Estenose e dezessete eram controles. O grupo Estenose apresentou menores valores de lordose lombopélvica total e lordose regional em L1, L2 e L3. Em pacientes com ECL e dor lombar, a lordose total lombopélvica e a lordose regional em L1, L2 e L3 eram menores. Naqueles com estenose e radiculopatia, houve valores maiores de desvio pélvico e lordose lombopélvica total e lordose regional em L1 e L2. Em pacientes com claudicação, lordose lombopélvica regional e compensação (offset) sagital em T9 foram menores. Todos os pacientes com dor tinham valores maiores de cifose torácica, lordose lombopélvica regional em L1, menores valores de desvio pélvico, offset sagital em T1, distância sacro-femoral e protuberância comparados com pacientes sem dor. Conclusões: O estudo mostra correlações significativas entre sintomas e parâmetros do eixo sagital entre pacientes com e sem ECL e também em subgrupos de pacientes com estenose e diferentes queixas.

Descritores: Coluna vertebral; Estenose espinal; Dor nas costas; Dor lombar; Imagem por ressonância magnética.

\section{RESUMEN}

Objetivo: Analizar la relación entre los parámetros del equilibrio sagital y los diversos síntomas de enfermedad espinal en pacientes con estenosis del canal lumbar (ECL) y sus controles. Métodos: En esta perspectiva, de estudio de diagnóstico, de control de casos, incluimos a todos los pacientes admitidos, consecutivamente, a un hospital universitario público para tratamiento quirúrgico de ECL, desde julio de 2010 hasta octubre de 2011, con más de 40 años de edad, con dolor de espaldas más radiculopatía o claudicación neurogénica, y controles sin ECL. La resonancia magnética y los rayos X permitieron hacer la medición de los parámetros del eje sagital. Los datos clínicos, el Índice de Incapacidad de Oswestry y la escala análoga, visual de dolor fueron evaluados. Resultados: 23 pacientes estuvieron en el grupo de Estenosis y 17 fueron los controles. El grupo de Estenosis presentó valores más bajos de lordosis lumbopélvica total y lordosis regional en L1, L2 y L3. En pacientes con ECL y dolores de espaldas, la lordosis lumbopélvica total y la regional, en L1, L2 y L3, fueron más leves.

1. MD, MsC. Department of Orthopaedics andTraumatology, Spinal Surgery Division, Universidade Estadual de Campinas (Unicamp) - Campinas, SP, Brasil. 2. MD. Department of Orthopaedics and Traumatology, Spinal Surgery Division, Universidade Estadual de Campinas (Unicamp) - Campinas, SP, Brasil.

3. MD, PhD. Department of Orthopaedics and Traumatology, Spinal Surgery Division, Universidade Estadual de Campinas (Unicamp) - Campinas, SP, Brasil.

Work performed in the Department of Orthopaedics and Traumatology, Spinal Surgery Division, Universidade Estadual de Campinas (Unicamp) - Campinas, SP, Brasil. Correspondence: Avenida Juriti, 73 - apto 252 A. São Paulo, SP, Brazil. 04520-000. pt.cavali@uol.com.br

Recebido em 25/05/2012, aceito em 22/08/2012 
Aquellos pacientes, con estenosis y radiculopatía, tuvieron valores más altos de inclinación pélvica y más leve lordosis lumbopélvica total y lordosis regional en L1 y L2. En pacientes con claudicación, la lordosis lumbopélvica regional en L1 y L2, y la compensación sagital en T9 fueron menos pronunciadas. En comparación con los pacientes que no sentían dolores, todos los pacientes con dolores tenían valores más altos de cifosis torácica y de lordosis lumbopélvica regional en L1, valores más bajos de inclinación pélvica, compensación sagital en T1, distancia sacrofemoral y saliente. Conclusiones: Este estudio muestra correlaciones importantes entre síntomas y parámetros del eje sagital referentes a pacientes con y sin estenosis del canal espinal, y también en subgrupos de los pacientes con estenosis que presentaron diversas quejas.

Descriptores: Columna vertebral; Estenosis espinal; Dolor de espaldas; Dolor de la región lumbar; Imágenes por resonancia magnética.

\section{INTRODUCTION}

Recent studies support the concept that the analysis of sagittal alignment of the spine is of fundamental importance in the diagnosis and therapy of degenerative diseases of the lumbar spine, especially when there is indication for surgical treatment, with instrumentation and fusion procedures included ${ }^{1-7}$. Several studies demonstrate the relationship between measurements of spinal and pelvic alignment in groups of normal subjects ${ }^{8-11}$ and in groups of patients with lumbar degenerative disease ${ }^{5,12}$, with statistically significant results, but still not clinically significant i.e., with heterogeneous clinical presentations $^{13-15}$. The differences in sagittal alignment between normal individuals and patients with lumbar degenerative diseases are not established, and it is not yet clear whether any measurement or standard value is associated with lumbar diseases ${ }^{16}$. The comparisons between groups of normal subjects and patients with degenerative lumbar disease (DLD) are conflicting; some studies showed no significant differences ${ }^{2,9}$, and others did show but with antagonistic results ${ }^{5,17}$.

The decrease of the sacral slope, the increase in the pelvic tilt and the decreased lumbar lordosis in patients with lumbar degenerative disease are findings for which there is greater agreement in the literature ${ }^{12,18,19}$. In a recent study of Chaléat-Valayer et al. ${ }^{16}$, with the largest series ever published, a decrease of the sacral slope and of the pelvic incidence was found in patients with lumbar degenerative disease.

The etiology of symptoms in patients with lumbar degenerative disease, such as back pain, radiculopathy and neurogenic claudication, is multifactorial and one symptom is present in different spinal diseases, such as disc herniation, lumbar stenosis or spondylolisthesis, with different anatomical features and pathophysiology 16,20,21. The difficulties in analyzing the results of previous studies may be due to the fact that it is possible to observe a symptom such as back pain, in groups of patients suffering from various degenerative diseases.

With the aim of better understand and apply the sagittal alignment analysis, this study examines the relationship between sagittal balance parameters and different symptoms of spine disease. To the best of our knowledge, this is the first time this evaluation is compared between a control group and group of patients with spinal canal stenosis, examining the relationships between sub-groups of patients separated by symptoms.

\section{METHODS}

\section{Study design and groups}

In this prospective, diagnostic, case-control study, we included all patients consecutively admitted to a public university hospital for surgical treatment of lumbar canal stenosis between July 2010 and October 2011, aged more than 40 years. The diagnosis of lumbar stenosis was confirmed by history, physical examination and a magnetic resonance imaging (MRI) exam evaluated by at least two surgeons from the Spine Surgery Service of Hospital das Clínicas, Universidade Estadual de Campinas (Unicamp). The complaint of all these patients was back pain plus radiculopathy or neurogenic claudication.

These symptomatic patients with a diagnosed lumbar stenosis were allocated in the Stenosis Group, and they were asked to indicate someone aged 40 years old or older, without a spine condition diagnosis, who would agree to participate in the study in the Control Group. The participants in this Control Group would be examined and undergo MRI scanning.

Participants with previous spine surgery, diabetes, polyneuropathy, alcoholism, other orthopedic pains and contraindications for $X$-rays exposure were excluded from the study.

This study was approved by the Ethics Committee of the Universidade Estadual de Campinas (protocols 0700.0.146.000-07 and 959-2007) and the data were collected only after the informed consent was obtained from all patients and participants in the control group.

Data were obtained by taking the history and clinical examination of all individuals. The symptoms analyzed were: back pain, radiculopathy and neurogenic claudication, recorded as present $(+)$ or absent (-). The symptom of claudication among the patients in the Stenosis group was also recorded as a continuous variable, registering the maximum distance the patient could walk in meters.

Due to the possibility that an individual could present more than one complaint, the most important was named as the main complaint, the second as secondary and, when the participant had more than two symptoms, the classification was "mixed complaint". Besides clinical examination, participants underwent sensory and motor neurological tests, application of the Oswestry Disability Index (ODI) questionnaire, visual analog scale of pain (VAS) and measures of the lumbar canal area (in $\mathrm{mm}^{2}$ ) and of the anteroposterior diameter $(\mathrm{mm})$ of the canal on MRI.

The assessment of sagittal alignment was performed using panoramic radiographs in the standing position called "clasped" 16. The subjects were instructed to stand upright with hands crossed in front of the pubis in lateral incidence (profile) and with the hands parallel to the body in the anteroposterior incidence. The distance between the radiographic apparatus and the film was maintained at $230 \mathrm{~cm}$ for all subjects, and the films were $30 \times 90 \mathrm{~cm}$, exposing from the skull base to the proximal femur.

\section{Vertebral parameters}

The vertebral parameters included in the analysis were: lumbar lordosis, thoracic kyphosis, sagittal vertical axis, anteroposterior listhesis, total lumbopelvic lordosis, regional lumbopelvic lordosis, sagittal axis in T1, T4 and T9, sagittal T1-L5 slope and sagittal offset in T1 and T9, which were recorded for this study according to the methods described below. Anteroposterior listhesis was recorded as the measure of the horizontal distance (in millimeters) horizontal, between the vertical line of the posterior wall of the upper vertebra and the vertical line of the posterior wall of the lower vertebra.

As shown schematically in Figure 1a, T4-T12 thoracic kyphosis ${ }^{22}$ was recorded as the angle between the upper plateau of T4 and the lower plateau of T12, measured based on the Cobb method. Lumbar lordosis was based on the angle of the upper plateau of S1 to the upper plateau of L1. Total lumbopelvic lordosis ${ }^{22}$ was recorded as the angle between the pelvic radius line (line segment between the center of femoral rotation and the posterior superior limit of S1) and the tangent line of the lower plateau of T12 (Figure 1a). Regional lumbopelvic lordosis ${ }^{22}$ was considered as the angle between the pelvic radius line and the lines tangent to the upper plateaus each of the lumbar vertebrae (Figure 1a).

Sagittal axis in $\mathrm{T} 1, \mathrm{~T} 9$ and $\mathrm{T} 4^{22}$ was recorded as the measure of the distance between the lines passing through the center of femoral 
rotation and the center of the vertebral bodies T1, T9 and T4 (Figure 1b). Sagittal offset in $\mathrm{T} 1$ and $\mathrm{Tg}^{22}$ was the angle between the vertical line and the plumb line passing between the centroid of T1 and T9 and the center of femoral rotation (Figure 1b).

Sagittal tilt in T1-L $5^{22}$ was the angle between the line connecting the center of the vertebral body of $T 1$ and $L 5$ and the vertical line (Figure 1c). Sagittal vertical axis (S1-C7) or sagittal slope ${ }^{22}$ was taken as the measure of the horizontal distance between the $\mathrm{C} 7$ line and the vertical line through the upper posterior limit of S1.

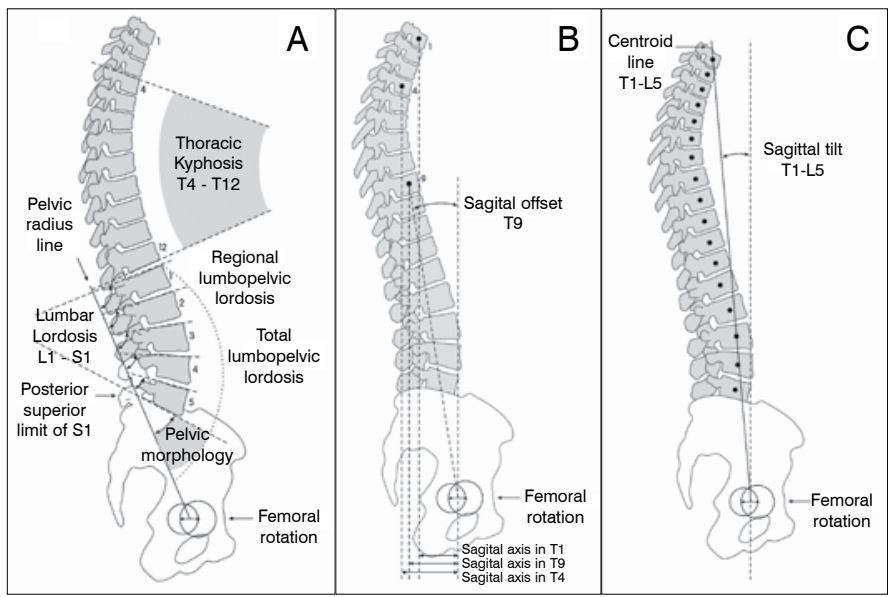

Figure 1. Vertebral measurements in imaging exams in this study. a) Thoracic kyphosis, lumbar lordosis (total and regional) and pelvic morphology. b) Sagittal axis and sagittal offset. c) Sagittal tilt.

\section{Pelvic parameters}

The pelvic parameters included in this study were the pelvic tilt, the sacral slope, the pelvic incidence, the pelvic morphology, the sacro-femoral angle, the sacro-femoral distance and the overhang, as shown schematically in Figure 2 and 3 and described in detail below.

The pelvic incidence ${ }^{23}$ is defined as the angle between the line perpendicular to the sacral plateau and the line connecting the midpoint of the plateau with the sacral center of femoral rotation. This morphological parameter is considered a constant, independent of the spatial orientation of the pelvis (Figure 2). The pelvic tilt ${ }^{23}$ corresponds to the angle between the line connecting the midpoint of the sacral plateau to the axis of femoral rotation and the vertical line. The sacral slope ${ }^{23}$ corresponds to the angle between the line of the sacral plateau and the horizontal line.

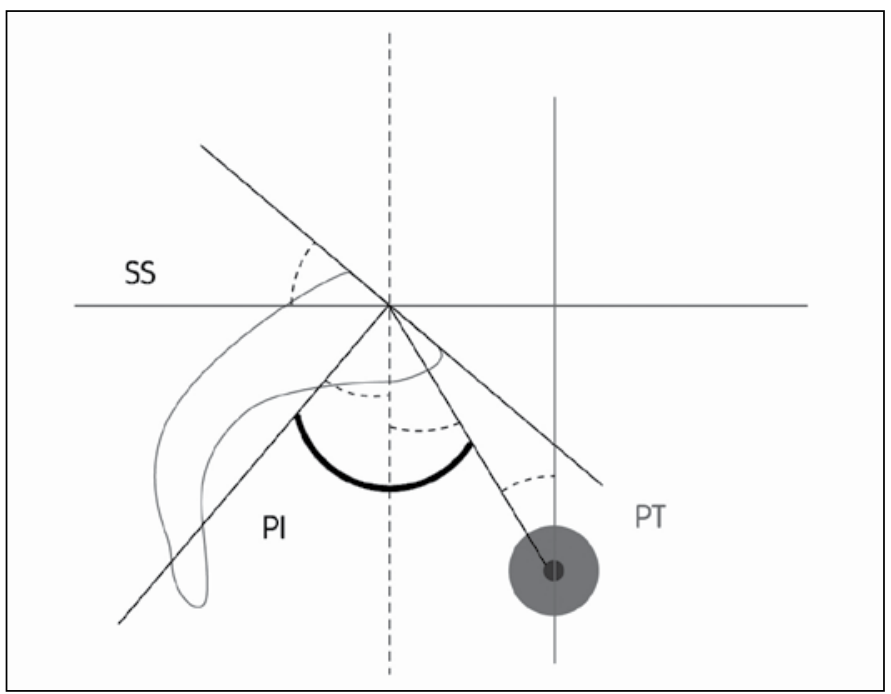

Figure 2. Pelvic angles in imaging exams in this study: sacral slope (SS), pelvic incidence $(\mathrm{PI})$ and pelvic tilt $(\mathrm{PT})$.
The pelvic morphology ${ }^{22}$ was considered as the angle between the pelvic radius line and the line along the upper plateau of S1 (Figure 1a).

The sacral inclination ${ }^{23}$ was the angle between the vertical line and the line tangent to the posterior wall of S1 (Figure 3a). The sacro-femoral angle ${ }^{24}$ was measured between the line of the upper plateau of S1 and the proximal femoral shaft axis (Figure 3b). The sacral-femoral distance ${ }^{24}$ was the distance (in $\mathrm{mm}$ ) between the plumb lines passing through the center of femoral rotation and the sacral promontory (Figure 3c). The overhang ${ }^{23}$ was the horizontal distance between vertical lines passing through the midpoint of the sacral plateau and the center of femoral rotation (Figure $3 \mathrm{~d}$ ).

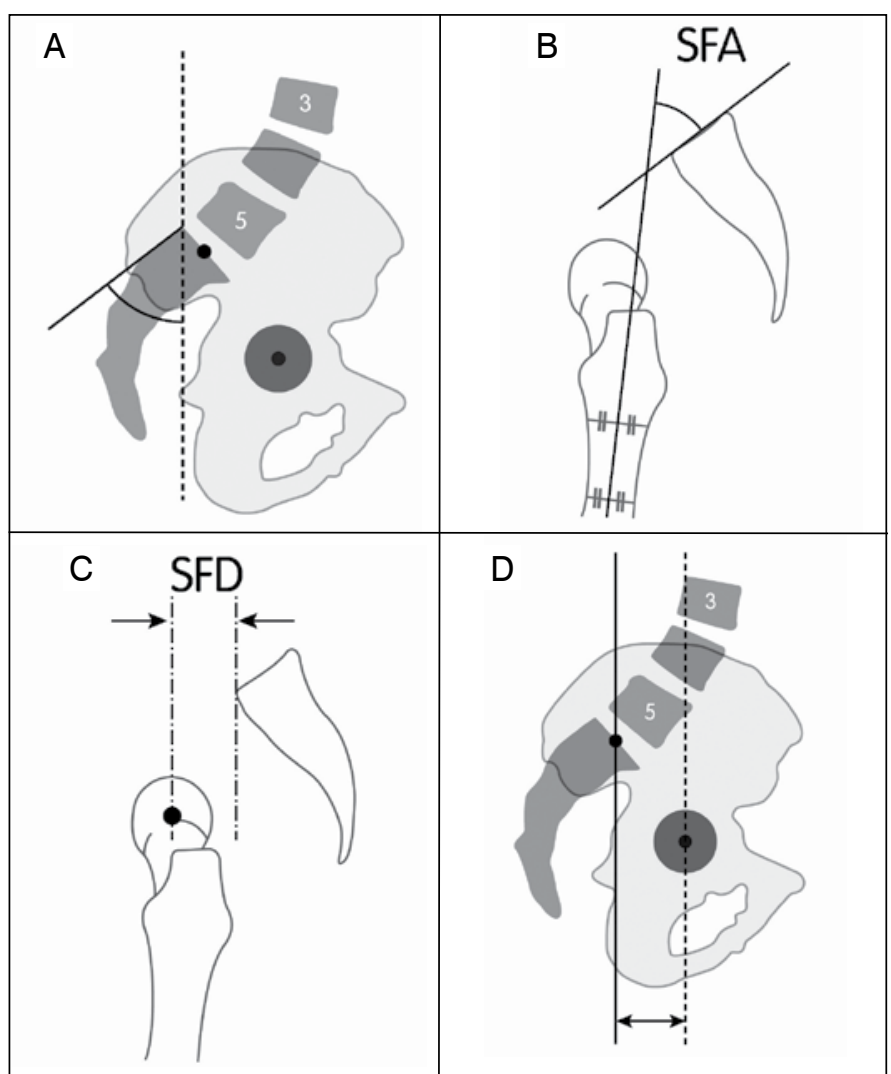

Figure 3. Sacro-femoral pelvic measurements in imaging exams in this study: a) sacral inclination; b) sacro-femoral angle (SFA); c) sacro-femoral distance (SFD) and d) overhang.

\section{STATISTICAL ANALYSIS}

Statistical correlations between clinical symptoms and parameters of sagittal alignment were searched between control group and stenosis group and its subgroups. These subgroups were formed according to the predominant complaint of patients in the stenosis as follows: low back pain subgroup, with the patients with a predominant complaint of low back pain, radiculopathy subgroup, claudication subgroup and mixed complaint group. In a second step, the correlations between clinical symptoms and parameters of sagittal alignment were searched between the stenosis group as a whole and the subgroups back pain, radiculopathy and claudication.

For the comparison between Stenosis and Control groups, qualitative measures were described as absolute and relative frequencies, and the association between these and the groups was tested using Fisher's exact test ${ }^{25}$. Quantitative measurements were described according to the groups as average, standard deviation, median, minimum and maximum values, and compared using the Mann-Whitney test ${ }^{25}$. To check the relationship between the radiographic measurements (diameter, angle and area) and the quantitative clinical measures of the Stenosis and Control groups, the Spearman correlation was calculated ${ }^{25}$

The tests were performed with a significance level of $5 \%(p<0.05)$. 


\section{RESULTS}

During the study period, 23 patients were evaluated and included in the Stenosis Group, and 17 as control subjects. In the Stenosis group, age ranged from 40 to 78 years (mean 55 years), with 10 women and 13 men. The Control group had the age ranging from 35 to 63 years (mean age of 50.5 years) with 11 females and 6 males. In this study, the description of symptoms and clinical variables by group are shown in Table 1. Low back pain as the main complaint was significantly more frequent in the Stenosis Group ( $p=0,005)$.

The MRI exams showed that the Stenosis group had significantly lower values in the cross-sectional areas at L3-L4, L4-L5 and L5$S 1$ ( $p<0.05)$, smaller diameters of the spinal canal in all lumbar vertebrae $(p=0.001)$ and higher values in the Oswestry Disability Index $(p=0.001)$ (Table 2).

Table 1. Description of the clinical variables according to the study groups.

\begin{tabular}{|c|c|c|c|c|c|c|c|}
\hline \multirow{3}{*}{ Variable } & \multirow{3}{*}{ Category } & \multicolumn{4}{|c|}{ Group } & \multirow{2}{*}{\multicolumn{2}{|c|}{ Total }} \\
\hline & & \multicolumn{2}{|c|}{ Control } & \multicolumn{2}{|c|}{ Stenosis } & & \\
\hline & & $n$ & $\%$ & $n$ & $\%$ & $n$ & $\%$ \\
\hline \multirow{2}{*}{ Gender } & Female & 11 & 64. & 10 & 43.5 & 21 & 52.5 \\
\hline & Male & 6 & 35.3 & 13 & 56.5 & 19 & 47.5 \\
\hline \multicolumn{8}{|c|}{ Main complaint } \\
\hline \multirow{2}{*}{ Low back pain } & Absent & 11 & 78.6 & 11 & 52.4 & 22 & 62.9 \\
\hline & Present & 3 & 21.4 & 10 & 47.6 & 13 & 37.1 \\
\hline \multirow{2}{*}{ Radiculopathy } & Absent & 13 & 92.9 & 17 & 81.0 & 30 & 85.7 \\
\hline & Present & 1 & 7.1 & 4 & 19.0 & 5 & 14.3 \\
\hline \multirow{2}{*}{ Claudication } & Absent & 14 & 100.0 & 18 & 85.7 & 32 & 91.4 \\
\hline & Present & 0 & 0.0 & 3 & 14.3 & 3 & 8.6 \\
\hline \multirow{2}{*}{ Deformity } & Absent & 14 & 100.0 & 20 & 95.2 & 34 & 97.1 \\
\hline & Present & 0 & 0.0 & 1 & 4.8 & 1 & 2.9 \\
\hline \multirow{2}{*}{ Mixed complaint } & Absent & 14 & 100.0 & 18 & 85.7 & 32 & 91.4 \\
\hline & Present & 0 & 0.0 & 3 & 14.3 & 3 & 8.6 \\
\hline \multicolumn{8}{|c|}{ Secondary complaint } \\
\hline \multirow{2}{*}{ Low back pain } & Absent & 14 & 100.0 & 12 & 57.1 & 26 & 74.3 \\
\hline & Present & 0 & 0.0 & 9 & 42.9 & 9 & 25.7 \\
\hline \multirow{2}{*}{ Radiculopathy } & Absent & 12 & 85.7 & 14 & 66.7 & 26 & 74.3 \\
\hline & Present & 2 & 14.3 & 7 & 33.3 & 9 & 25.7 \\
\hline \multirow{2}{*}{ Claudication } & Absent & 14 & 100.0 & 16 & 76.2 & 30 & 85.7 \\
\hline & Present & 0 & 0.0 & 5 & 23.8 & 5 & 14.3 \\
\hline
\end{tabular}

Comparing the Stenosis group and the Control group according to the radiographic data that make up the sagittal alignment, it is observed that the Stenosis group presents lower values of total lumbopelvic lordosis $(p=0.006)$ and regional lordosis L1, L2 and L3 $(p<0.026)$. None of the other vertebral and pelvic variables were significantly different between groups (Table 3).

In patients with stenosis and complaining of back pain, total lumbopelvic lordosis and the regional lordosis at L1, L2 and L3 are significantly lower $(p<0.05)$ compared to the Control group. The patients with stenosis and radiculopathy complaint also have a higher value of pelvic tilt ( $p=0.004)$ and lower values for total lumbopelvic lordosis and regional lordosis in L1 and $L 2(p<0.05)$ than the control participants. In patients with stenosis and a complaint of claudication, regional lumbopelvic lordosis in $L 1$ and $L 2$ and the T9 sagittal offset $(p=0.045)$ were smaller than in the control group ( $p=0.050$ and 0.029 respectively).

The correlations between the variables of sagittal alignment and neurogenic claudication show that the thoracic kyphosis $(p=0.005)$, lumbar lordosis L1-S1 ( $p=0.043)$ and T9 sagittal offset $(p=0.002)$ are directly related, while listhesis in L4-L5 $(p=0.021)$, T4 sagittal axis $(p=0.041)$ and T9 sagittal axis $(0.045)$ are inversely related (Table 4).

All patients complaining of back pain had higher values of thoracic kyphosis $(p=0.035)$, regional lumbopelvic lordosis in L1 $(p=0.028)$, lower values for pelvic tilt $(p=0.029)$, sagittal T1 offset $(p=0.022)$, sacro-femoral distance $(p=0.014)$ and overhang $(p=0.035)$ compared to patients without the complaint (Table 5).

In the group Stenosis, patients with radiculopathy were less prone to have regional lordosis in L2, L3 and L4 ( $p=0.047$, $p=0.047$ and $p=0.023$ respectively).

Patients with complaints of claudication had lower values for pelvic tilt and overhang than the patients with stenosis without complaints of claudication ( $p=0.002$ and $p=0.020$ respectively), while the total lumbopelvic lordosis is greater in patients complaining of claudication ( $p=0.007$ ). Patients with mixed complaints had higher values of T1 ( $P=0.014)$ and T4 sagittal axis $(p=0.023)$.

An inverse relationship was observed, among all patients in the stenosis group, between the results of the analogue scale of pain and the presence of regional lumbopelvic lordosis in $\mathrm{L} 2$ and $\mathrm{L} 3$ $(p<0.035)$ (Table 6)

In patients with complaints of radiculopathy, there was an inverse relationship between pain and lumbar lordosis $(p=0.011)$, sacral inclination $(p=0.002)$, total lumbopelvic lordosis $(p=0.013)$, sacral slope $(p=0.007)$ and regional lumbopelvic lordosis in $L 1$ and $L 2$ ( $p=0.010$ and $p=0.015$ respectively) (Table 6$)$.

Table 2. Correlation between the Oswestry Disability Index and the magnetic resonance imaging measurements according to the study groups and $p$ values (Spearman's test).

\begin{tabular}{|c|c|c|c|c|c|c|c|c|c|c|c|c|c|}
\hline \multirow{2}{*}{ Variable } & \multicolumn{6}{|c|}{ Control } & \multicolumn{6}{|c|}{ Stenosis } & \multirow{2}{*}{$\mathbf{p}$} \\
\hline & Mean & Standard deviation & Median & Minimum & Maximum & $\mathbf{n}$ & Mean & Standard deviation & Median & Minimum & Maximum & $\mathrm{n}$ & \\
\hline Oswestry (\%) & 11,80 & 17,88 & 6 & 0 & 68 & 15 & 45,59 & 17,39 & 44 & 20 & 68 & 17 & $<0,001$ \\
\hline L1-L2 & 159,50 & 33,55 & 150 & 131 & 207 & 4 & 161,13 & 48,90 & 181,5 & 88 & 225 & 16 & 0,892 \\
\hline L2-L3 & 180,69 & 47,23 & 176 & 117 & 253 & 13 & 141,39 & 52,84 & 141 & 33 & 232 & 23 & 0,060 \\
\hline L5-S1 & 166,94 & 51,24 & 153 & 92 & 244 & 16 & 118,30 & 76,11 & 87 & 29 & 316 & 23 & 0,011 \\
\hline \multicolumn{14}{|c|}{ Canal diameter } \\
\hline L1-L2 & 15,03 & 2,01 & 14,6 & 10,7 & 18,4 & 16 & 11,60 & 2,69 & 12,2 & 6,3 & 16,1 & 23 & $<0,001$ \\
\hline L2-L3 & 13,69 & 1,59 & 13,95 & 10,6 & 15,9 & 16 & 10,26 & 3,10 & 10,7 & 4,3 & 15 & 23 & $<0,001$ \\
\hline
\end{tabular}


Table 3. Description of the magnetic resonance imaging findings according to the spine level and study groups and $p$ values.

\begin{tabular}{c|c|c|c|c|c|c|c|c|c|c|c|c|c}
\hline \multirow{2}{*}{ Variable } & \multicolumn{9}{|c|}{ Control } & \multicolumn{5}{c|}{ Stenosis } \\
\cline { 2 - 19 } & Mean & SD & Median & Minimum & Maximum & $\mathbf{n}$ & Mean & SD & Median & Minimum & Maximum & $\mathbf{n}$ & $\mathbf{p}$ \\
\hline Coronal imbalance & 4,20 & 5,82 & 0 & 0 & 15 & 15 & 15,10 & 21,35 & 7,5 & 0 & 78 & 20 & 0,122 \\
\hline Thoracic kyphosis (T4-T12) & 40,87 & 9,83 & 41 & 25 & 59 & 15 & 35,30 & 11,50 & 38,5 & 14 & 52 & 20 & 0,240 \\
\hline Lumbar lordosis (L1S1) & 59,93 & 10,67 & 59 & 48 & 81 & 15 & 48,00 & 18,17 & 50 & 20 & 80 & 20 & 0,064 \\
\hline Sagittal vertical axis (C7S1) & $-2,27$ & 22,33 & -5 & -35 & 50 & 15 & 8,80 & 38,08 & 10 & -100 & 70 & 20 & 0,107 \\
\hline Pelvic tilt & 13,00 & 5,57 & 14 & 5 & 25 & 15 & 15,65 & 7,65 & 17 & 5 & 29 & 20 & 0,179 \\
\hline Sacral slope & 41,27 & 10,31 & 40 & 26 & 60 & 15 & 36,35 & 12,53 & 35 & 13 & 67 & 20 & 0,202 \\
\hline Sacral inclination angle & 45,87 & 6,50 & 46 & 33 & 54 & 15 & 44,05 & 13,14 & 44,5 & 6 & 63 & 20 & 0,805 \\
\hline Pelvic inclination & 52,33 & 14,73 & 51 & 29 & 82 & 15 & 50,35 & 14,82 & 51 & 32 & 80 & 20 & 0,610 \\
\hline
\end{tabular}

Anterior-posterior listhesis (mm)

\begin{tabular}{c|c|c|c|c|c|c|c|c|c|c|c|c|c}
\hline L1-L2 & 0,34 & 0,90 & 0 & 0 & 3 & 15 & 0,37 & 1,21 & 0 & 0 & 5 & 19 & 0,681 \\
\hline L2-L3 & 0,74 & 1,33 & 0 & 0 & 4 & 15 & 0,58 & 1,43 & 0 & 0 & 5 & 19 & 0,493 \\
\hline L3-L4 & 0,88 & 1,68 & 0 & 0 & 5 & 15 & 1,21 & 4,60 & 0 & 0 & 20 & 19 & 0,302 \\
\hline L4-L5 & 0,21 & 0,77 & 0 & 0 & 3 & 15 & 1,01 & 3,21 & 0 & 0 & 13 & 19 & 0,891 \\
\hline L5-S1 & 0,01 & 0,02 & 0 & 0 & 0,09 & 15 & 0,26 & 1,15 & 0 & 0 & 5 & 19 & 0,973 \\
\hline Total lumbar-pelvic lordosis & 93,29 & 7,18 & 93 & 76 & 102 & 14 & 80,47 & 15,56 & 83 & 40 & 100 & 19 & 0,006 \\
\hline
\end{tabular}

Regional lumbar-pelvic lordosis

\begin{tabular}{c|c|c|c|c|c|c|c|c|c|c|c|c|c}
\hline L1 & 93,71 & 4,48 & 92,5 & 88 & 103 & 14 & 81,11 & 13,10 & 85 & 55 & 100 & 19 & 0,001 \\
\hline$L 2$ & 91,43 & 4,96 & 90,5 & 85 & 98 & 14 & 78,00 & 17,46 & 82 & 23 & 100 & 19 & 0,002 \\
\hline$L 3$ & 89,21 & 12,58 & 88 & 74 & 111 & 14 & 76,11 & 18,14 & 75 & 25 & 110 & 19 & 0,026 \\
\hline$L 4$ & 84,00 & 19,36 & 75,5 & 65 & 118 & 14 & 73,68 & 22,52 & 70 & 30 & 126 & 19 & 0,114 \\
\hline L5 & 80,14 & 33,21 & 64 & 50 & 132 & 14 & 70,95 & 31,35 & 61 & 33 & 140 & 19 & 0,397 \\
\hline Pelvic morphology & 63,29 & 47,21 & 40 & 14 & 150 & 14 & 47,79 & 38,62 & 40 & 8 & 175 & 19 & 0,602 \\
\hline
\end{tabular}

\section{Sagittal axis}

\begin{tabular}{l|c|c|c|c|c|c|c|c|c|c|c|c|c} 
T1 & $-26,08$ & 46,93 & -35 & -86 & 70 & 13 & $-10,47$ & 45,15 & -10 & -83 & 105 & 19 & 0,195 \\
\hline T4 & $-42,08$ & 62,55 & -57 & -115 & 80 & 13 & $-34,11$ & 46,05 & -30 & -105 & 75 & 19 & 0,426 \\
\hline T9 & $-43,92$ & 67,28 & -65 & -117 & 79 & 13 & $-44,63$ & 47,90 & -50 & -93 & 60 & 19 & 0,677 \\
\hline
\end{tabular}

Sagittal offset

\begin{tabular}{c|c|c|c|c|c|c|c|c|c|c|c|c|c}
\hline T1 & 6,46 & 3,31 & 7 & 0 & 10 & 13 & 5,00 & 3,40 & 5 & 0 & 12 & 19 & 0,170 \\
\hline T9 & 12,92 & 2,84 & 13 & 9 & 21 & 13 & 8,79 & 8,19 & 10 & -13 & 20 & 19 & 0,126 \\
\hline Sagittal inclination T1-T5 & 9,07 & 5,76 & 8,5 & 2 & 26 & 14 & 9,89 & 8,25 & 7 & 0 & 25 & 19 & 0,706 \\
\hline Sacro-femoral angle & 42,38 & 21,12 & 42 & 10 & 90 & 13 & 52,33 & 15,25 & 50 & 15 & 78 & 18 & 0,082 \\
\hline Sacro-femoral distance & 7,38 & 15,80 & 10 & -32 & 24 & 13 & 12,00 & 22,27 & 13 & -25 & 60 & 18 & 0,622 \\
\hline Overhang & 20,50 & 12,94 & 20 & 2 & 47 & 14 & 25,42 & 17,33 & 25 & 2 & 63 & 19 & 0,529 \\
\hline
\end{tabular}


Table 4. Correlation between the alignment variables, age and claudication.

\begin{tabular}{|c|c|c|c|}
\hline \multicolumn{2}{|l|}{ Correlation } & Age & Claudication \\
\hline \multirow{2}{*}{ Coronal imbalance } & $r$ & 0,064 & 0,124 \\
\hline & $p$ & 0,787 & 0,602 \\
\hline \multirow{2}{*}{ Thoracic kyphosis (T4-T12) } & $r$ & $-0,257$ & 0,607 \\
\hline & $p$ & 0,274 & 0,005 \\
\hline \multirow{2}{*}{ Lumbar lordosis (L1S1) } & $r$ & $-0,178$ & 0,457 \\
\hline & $p$ & 0,452 & 0,043 \\
\hline \multirow{2}{*}{ Vertical sagittal axis (C7S1) } & $r$ & $-0,011$ & $-0,213$ \\
\hline & $p$ & 0,963 & 0,366 \\
\hline Pelvic tilt & $\frac{1}{n}$ & $\begin{array}{l}0,018 \\
0,941\end{array}$ & 0,077 \\
\hline \multirow{2}{*}{ Sacral slope } & $\frac{r}{r}$ & 0,050 & $\frac{0,49}{0,090}$ \\
\hline & $\mathrm{p}$ & 0,835 & 0,705 \\
\hline \multirow{2}{*}{ Sacral inclination } & $r$ & $-0,094$ & 0,019 \\
\hline & $\mathrm{p}$ & 0,693 & 0,935 \\
\hline \multirow{2}{*}{ Pelvic inclination } & r & 0,144 & 0,122 \\
\hline & $\mathrm{p}$ & 0,546 & 0,607 \\
\hline \multirow{2}{*}{ Total lombopelvic lordosis } & r & $-0,203$ & 0,170 \\
\hline & $\mathrm{p}$ & 0,404 & 0,486 \\
\hline \multicolumn{4}{|c|}{ Regional lombopelvic lordosis } \\
\hline \multirow{2}{*}{ L1 } & $\mathrm{r}$ & $-0,229$ & 0,257 \\
\hline & $p$ & 0,345 & 0,287 \\
\hline \multirow{2}{*}{ L2 } & r & $-0,271$ & 0,307 \\
\hline & $p$ & 0,262 & 0,202 \\
\hline \multirow{2}{*}{ L3 } & r & $-0,104$ & 0,234 \\
\hline & $\mathrm{p}$ & 0,672 & 0,335 \\
\hline \multirow{2}{*}{$\llcorner 4$} & r & 0,081 & 0,075 \\
\hline & $\mathrm{p}$ & 0,742 & 0,759 \\
\hline L5 & r & 0,176 & 0,051 \\
\hline \multirow{2}{*}{ Pelvic morphology } & $\frac{p}{r}$ & 0,471 & $\frac{0,837}{-0,384}$ \\
\hline & $\frac{1}{p}$ & 0,268 & $0.0,105$ \\
\hline \multicolumn{4}{|c|}{ Sagittal axis } \\
\hline \multirow{2}{*}{$\mathrm{T1}$} & $r$ & 0,222 & $-0,285$ \\
\hline & $\mathrm{p}$ & 0,360 & 0,238 \\
\hline \multirow{2}{*}{$\mathrm{T} 4$} & $r$ & 0,383 & $-0,472$ \\
\hline & $\mathrm{p}$ & 0,106 & 0,041 \\
\hline \multirow{2}{*}{ T9 } & r & 0,442 & $-0,465$ \\
\hline & $\mathrm{p}$ & 0,058 & 0,045 \\
\hline \multicolumn{4}{|c|}{ Sagittal offset } \\
\hline \multirow{2}{*}{$\mathrm{T} 1$} & $r$ & $-0,177$ & 0,005 \\
\hline & $p$ & 0,469 & 0,983 \\
\hline T9 & $r$ & $-0,495$ & 0,664 \\
\hline & $p$ & 0,031 & 0,002 \\
\hline Sagittal inclination $T 1 T 5$ & $\frac{r}{n}$ & 0,243 & 0,075 \\
\hline & $\frac{p}{p}$ & 0,316 & 0,760 \\
\hline Sacro-femoral angle & $\frac{1}{p}$ & $\frac{0,125}{0621}$ & $\begin{array}{l}-0,094 \\
0,710\end{array}$ \\
\hline Sacro-femoral distance & $r$ & $-0,121$ & $-0,066$ \\
\hline Sacio-eminord aistance & $\mathrm{p}$ & 0,633 & 0,795 \\
\hline Overhang & $r$ & 0,021 & 0,037 \\
\hline 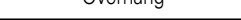 & $p$ & 0,931 & 0,879 \\
\hline
\end{tabular}

\section{DISCUSSION}

Conflicting results come from studies ${ }^{4,26,27}$ that try to correlate the data of the sagittal alignment parameters. Some authors conclude that no significant differences can be found between controls and individuals with low back pain ${ }^{2,9}$, and others, such as the study by Barrey et al. ${ }^{18}$, were able to show significant differences. Some features in these studies could explain the contradiction in their results: one is the fact that many lumbar spine diseases have similar symptoms, especially low back pain, which can also be associated to radiculopathy and claudication. It is difficult to interpret the data from the evaluation of patients with low back pain with different degenerative diseases of the spine. Our study, however, examined only patients with a defined disease: lumbar canal stenosis (LCS), and these individuals were paired with controls with the same age, socioeconomic status and origins. Therefore, this is the first time that the significant differences found in the comparison between patients and controls can have a possible clinical interpretation.

The present study has shown a significant reduction of total lumbopelvic lordosis in the group of patients with stenosis and also in the regional lumbopelvic lordosis, in L1, L2 and L3. These results are different from those in previous studies ${ }^{12,18}$, which compared the sagittal alignment parameters in patients with low back pain and healthy controls: in those studies, the patients with pain had significant reduction of the sacral slope and lumbar lordosis and a significant increase in the pelvic tilt. However, these findings are expected in the ageing process and degenerative disease of the spine and pelvis ${ }^{11,23}$. The most recent and larger study published ${ }^{16}$ has shown a reduction in the sacral slope and in pelvic incidence in the patients with low back pain. The authors explained the reduction in the pelvic tilt through the compensation mechanism of pelvic retroversion. We did not observe this: our study has not shown a reduction in the sacral slope or increase in pelvic tilt in the Stenosis group. The data suggest that patients with stenosis have a significantly reduced lordosis, but they do not present pelvic retroversion as a compensation mechanism.

When we divided the Stenosis group in three, according to the predominance of symptoms (low back pain, radiculopathy and claudication) and compared each of these subgroups with the control group, we could observe that the reduction in lumbar lordosis was

Table 5. Sagittal alignment variables according to the presence of low back pain in patients with lunbar spinal canal stenosis and $p$ values.

\begin{tabular}{|c|c|c|c|c|c|c|c|c|c|c|c|c|c|}
\hline \multirow{3}{*}{ Variable } & \multicolumn{12}{|c|}{ Low back pain } & \multirow{3}{*}{$\mathbf{p}$} \\
\hline & \multicolumn{6}{|c|}{ Absent } & \multicolumn{6}{|c|}{ Present } & \\
\hline & Mean & SD & Median & Minimum & Maximum & $\mathrm{n}$ & Mean & SD & Median & Minimum & Maximum & $\mathbf{n}$ & \\
\hline Coronal imbalance & 16,80 & 26,87 & 3,5 & 0 & 78 & 10 & 13,40 & 15,28 & 13,5 & 0 & 50 & 10 & 0,684 \\
\hline Thoracic kyphosis (T4-T12) & 29,60 & 10,57 & 29,5 & 14 & 45 & 10 & 41,00 & 9,76 & 42,5 & 20 & 52 & 10 & 0,035 \\
\hline Pelvic tilt & 19,80 & 7,10 & 20 & 5 & 29 & 10 & 11,50 & 5,91 & 10 & 5 & 20 & 10 & 0,029 \\
\hline Sacral slope & 36,10 & 13,22 & 35 & 13 & 60 & 10 & 36,60 & 12,51 & 35 & 22 & 67 & 10 & 0,971 \\
\hline Sacral inclination & 38,60 & 13,93 & 41 & 6 & 59 & 10 & 49,50 & 10,22 & 52,5 & 31 & 63 & 10 & 0,063 \\
\hline Pelvic inclination & 54,00 & 16,73 & 55,5 & 32 & 80 & 10 & 46,70 & 12,43 & 45,5 & 32 & 74 & 10 & 0,218 \\
\hline \multicolumn{14}{|c|}{ Anterior-posterior listhesis (mm) } \\
\hline L3-L4 & 0,33 & 1,00 & 0 & 0 & 3 & 9 & 2,00 & 6,32 & 0 & 0 & 20 & 10 & 1,000 \\
\hline L4-L5 & 2,12 & 4,53 & 0 & 0 & 13 & 9 & 0,00 & 0,00 & 0 & 0 & 0 & 10 & 0,243 \\
\hline L5-S1 & 0,56 & 1,67 & 0 & 0 & 5 & 9 & 0,00 & 0,00 & 0 & 0 & 0 & 10 & 0,720 \\
\hline Total lombopelvic lordosis & 73,11 & 17,44 & 78 & 40 & 94 & 9 & 87,10 & 10,54 & 88 & 65 & 100 & 10 & 0,065 \\
\hline \multicolumn{14}{|c|}{ Regional lombopelvic lordosis } \\
\hline $\mathrm{L} 1$ & 74,22 & 13,82 & 80 & 55 & 93 & 9 & 87,30 & 9,14 & 89 & 65 & 100 & 10 & 0,028 \\
\hline $\mathrm{L} 2$ & 70,78 & 22,20 & 73 & 23 & 100 & 9 & 84,50 & 8,53 & 84 & 64 & 95 & 10 & 0,113 \\
\hline $\mathrm{L} 3$ & 70,33 & 23,10 & 68 & 25 & 110 & 9 & 81,30 & 10,99 & 80 & 65 & 96 & 10 & 0,113 \\
\hline \multirow{2}{*}{\multicolumn{14}{|c|}{ Sagittal offset }} \\
\hline & & & & & & & & & & & & & \\
\hline$T 1$ & 6,89 & 3,14 & 6 & 2 & 12 & 9 & 3,30 & 2,75 & 4 & 0 & 8 & 10 & 0,022 \\
\hline T9 & 8,33 & 9,72 & 10 & -13 & 20 & 9 & 9,20 & 7,05 & 9,5 & -6 & 18 & 10 & 0,968 \\
\hline Sagittal inclination T1T5 & 9,44 & 5,98 & 8 & 0 & 20 & 9 & 10,30 & 10,20 & 7 & 0 & 25 & 10 & 0,661 \\
\hline Sacro-femoral angle & 53,11 & 18,11 & 53 & 15 & 75 & 9 & 51,56 & 12,85 & 50 & 30 & 78 & 9 & 0,605 \\
\hline Sacro-femoral distance & 24,89 & 16,74 & 18 & 10 & 60 & 9 & $-0,89$ & 19,98 & 0 & -25 & 35 & 9 & 0,014 \\
\hline Overhang & 35,33 & 17,56 & 27 & 8 & 63 & 9 & 16,50 & 11,82 & 10 & 2 & 35 & 10 & 0,035 \\
\hline
\end{tabular}


Table 6. Correlation ( $p$ values) between the main complaints of patients and the alignment variables (Mann-Whitney test).

\begin{tabular}{|c|c|c|c|c|c|}
\hline \multicolumn{2}{|l|}{ Correlation } & Radiculopathy & Low back pain* & Claudication & Total \\
\hline \multirow{2}{*}{ Coronal imbalance } & $\mathrm{r}$ & 0,269 & $-0,002$ & $-0,312$ & 0,133 \\
\hline & $p$ & 0,484 & 0,995 & 0,496 & 0,599 \\
\hline \multirow{2}{*}{ Thoracic kyphosis (T4-T12) } & $\mathrm{r}$ & $-0,652$ & $-0,413$ & $-0,171$ & $-0,428$ \\
\hline & $p$ & 0,057 & 0,112 & 0,713 & 0,077 \\
\hline \multirow{2}{*}{ Lumbar lordosis (L1S1) } & $r$ & $-0,792$ & $-0,064$ & 0,412 & $-0,207$ \\
\hline & $p$ & 0,011 & 0,814 & 0,359 & 0,410 \\
\hline \multirow{2}{*}{ Vertical sagittal axis (C7S1) } & $r$ & $-0,127$ & 0,280 & 0,397 & 0,145 \\
\hline & $p$ & 0,746 & 0,294 & 0,379 & 0,565 \\
\hline \multirow{2}{*}{ Pelvic tilt } & $r$ & $-0,142$ & 0,148 & $-0,255$ & 0,200 \\
\hline & $p$ & 0,715 & 0,585 & 0,581 & 0,425 \\
\hline \multirow{2}{*}{ Sacral slope } & $r$ & $-0,819$ & $-0,178$ & 0,655 & $-0,339$ \\
\hline & $p$ & 0,007 & 0,509 & 0,110 & 0,169 \\
\hline \multirow{2}{*}{ Sacral inclination } & $r$ & $-0,878$ & $-0,115$ & 0,487 & $-0,286$ \\
\hline & $p$ & 0,002 & 0,672 & 0,268 & 0,250 \\
\hline \multirow{2}{*}{ Pelvic inclination } & $r$ & $-0,621$ & 0,027 & 0,187 & $-0,113$ \\
\hline & $p$ & 0,074 & 0,920 & 0,688 & 0,656 \\
\hline \multicolumn{6}{|c|}{ Anterior-posterior listhesis (mm) } \\
\hline \multirow{2}{*}{ L1-L2 } & $r$ & $\cdot$ & $-0,591$ & $-0,817$ & $-0,573$ \\
\hline & $p$ & & 0,016 & 0,025 & 0,016 \\
\hline \multirow{2}{*}{ L2-L3 } & $r$ & $-0,168$ & $-0,565$ & $-0,817$ & $-0,528$ \\
\hline & $p$ & 0,691 & 0,023 & 0,025 & 0,030 \\
\hline \multirow{2}{*}{ L3-L4 } & $r$ & 0,504 & 0,037 & $-0,535$ & 0,034 \\
\hline & $p$ & 0,203 & 0,892 & 0,216 & 0,898 \\
\hline \multirow{2}{*}{ L4-L5 } & $r$ & & $-0,216$ & $-0,350$ & $-0,178$ \\
\hline & $p$ & . & 0,422 & 0,441 & 0,495 \\
\hline \multirow{2}{*}{ L5-S1 } & $r$ & & $-0,404$ & $-0,535$ & $-0,393$ \\
\hline & $p$ & . & 0,120 & 0,216 & 0,119 \\
\hline & $\mathrm{r}$ & $-0,819$ & $-0,244$ & 0,337 & $-0,378$ \\
\hline 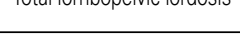 & $p$ & 0,013 & 0,380 & 0,460 & 0,135 \\
\hline & & onal lombopelvi & lordosis & & \\
\hline 11 & $r$ & $-0,836$ & $-0,230$ & 0,337 & $-0,394$ \\
\hline$L_{1}$ & $p$ & 0,010 & 0,409 & 0,460 & 0,117 \\
\hline 2 & $r$ & $-0,807$ & $-0,444$ & $-0,350$ & $-0,549$ \\
\hline & $p$ & 0,015 & 0,097 & 0,442 & 0,022 \\
\hline 3 & $r$ & $-0,651$ & $-0,395$ & $-0,449$ & $-0,513$ \\
\hline Lo & $p$ & 0,081 & 0,145 & 0,312 & 0,035 \\
\hline 1 & $r$ & $-0,261$ & $-0,239$ & $-0,198$ & $-0,357$ \\
\hline & $p$ & 0,533 & 0,392 & 0,670 & 0,160 \\
\hline 5 & $r$ & $-0,297$ & $-0,306$ & $-0,281$ & $-0,389$ \\
\hline LU & $p$ & 0,475 & 0,267 & 0,542 & 0,122 \\
\hline Pelvir mornholnay & $r$ & $-0,158$ & $-0,122$ & $-0,028$ & $-0,194$ \\
\hline 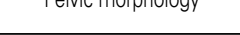 & $p$ & 0,709 & 0,665 & 0,952 & 0,456 \\
\hline & & Sagittal axis & & & \\
\hline$T_{1}$ & $r$ & 0,241 & 0,339 & 0,730 & 0,274 \\
\hline & $p$ & 0,565 & 0,217 & 0,063 & 0,287 \\
\hline$T A_{1}$ & $r$ & 0,139 & 0,110 & 0,000 & 0,029 \\
\hline & $p$ & 0,742 & 0,697 & 1,000 & 0,913 \\
\hline TO & $r$ & 0,157 & 0,140 & 0,000 & $-0,002$ \\
\hline 19 & $p$ & 0,711 & 0,618 & 1,000 & 0,994 \\
\hline & & Sagittal offse & & & \\
\hline$T 1$ & $r$ & 0,118 & $-0,240$ & $-0,529$ & $-0,152$ \\
\hline & $p$ & 0,781 & 0,389 & 0,222 & 0,561 \\
\hline TO & $r$ & $-0,201$ & $-0,145$ & $-0,264$ & $-0,154$ \\
\hline 10 & $p$ & 0,633 & 0,606 & 0,567 & 0,555 \\
\hline Sacittal inclination T1T5 & $r$ & $-0,479$ & $-0,186$ & 0,151 & $-0,140$ \\
\hline & $p$ & 0,230 & 0,508 & 0,746 & 0,592 \\
\hline Corntomentand & $r$ & 0,556 & 0,334 & 0,576 & 0,462 \\
\hline 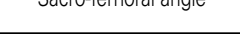 & $p$ & 0,153 & 0,224 & 0,176 & 0,062 \\
\hline Sacrefemoral distance & $r$ & $-0,333$ & $-0,318$ & $-0,655$ & $-0,179$ \\
\hline 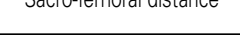 & $p$ & 0,420 & 0,248 & 0,110 & 0,493 \\
\hline Overhang & $r$ & 0,229 & 0,130 & $-0,147$ & 0,233 \\
\hline . & $p$ & 0,586 & 0,645 & 0,753 & 0,367 \\
\hline
\end{tabular}

present in all of them, but an increase in the pelvic tilt was seen in the radiculopathy group and a reduction in the sagittal offset in T9 was seen in the group with claudication. A possible explanation for the increase in the pelvic tilt in the radiculopathy subgroup could be indeed the compensation mechanism of pelvic retroversion. Otherwise, the reduction in the T9 sagittal offset could possibly be explained by a compensation mechanism of anteriorization of the spine to increase the lumbar canal area. Patients in our study who walked longer distances had significantly higher values of thoracic kyphosis, lumbar lordosis and sagittal offset in T9 and lower values of sagittal axis in T4 and T9. These data could reflect a better compensation and a reduced stenosis.

Another interesting finding in our study was that patients with low back pain had higher values of thoracic kyphosis and lumbopelvic lordosis in L1, and lower values of pelvic tilt, sagittal offset in T1, sacral-femoral distance and overhang. There are not studies in the literature showing these correlations or explaining this phenomenon. Our results suggest that patients with low back pain present lower pelvic retroversion and higher thoracic kyphosis than patients in the Stenosis group without low back pain.

The lower pelvic retroversion could be an explanation to the lower values of pelvic tilt, overhang and higher total lumbopelvic lordosis in the group of claudication as well.

A significant reduction in the values of regional lordosis in $L 3, L 4$ and L5 was observed in this study in the subgroup of patients with radiculopathy. There are no studies in the literature reporting this correlation. A possible explanation would be that, in this subgroup, the foraminal narrowing would be more important than the lordosis.

The subgroup with mixed complaints has shown an increase in the values of sagittal axis in T1 and T4. In these patients, there can be retroversion of the pelvis with a greater distance of the sacrum to the femoral rotation axis.

The correlation between the visual analogue scale (VAS) and the sagittal axis parameters in the subgroup with low back pain observed in our study shows that the higher the value of VAS, the lower are the values of regional lordosis in L2 and L3. By measuring the lordosis in different regions, this study opens a new window of investigative opportunity: the possibility that the lordosis in higher levels of the spine may have some interference in the symptoms of the lordosis in lower levels.

In the subgroup of patients with radiculopathy, the higher the value in VAS, the lower were the values in lumbar lordosis in L1-L5, sacral tilt, total lumbopelvic lordosis and sacral slope. Among our patients with radiculopathy, the stenosis was mainly lateral, and maybe this explains why the lordosis in these individuals did not interfere with pain. However, this assumption requires further investigation.

By searching correlations between the measurements and different clinical symptoms such as pain, radiculopathy and claudication, our study foresees a possible explanation for the clinical picture of patients with degenerative diseases of the spine. The association between imaging and symptomatology allows the treatment to be planned individually: even for some patients without lordosis, for example, a simple correction of a lateral stenosis can be enough in the subgroup with radiculopathy, without the need of osteotomy for correction of the lordosis. The patients in the Stenosis group in this study would have the same treatment, with the correction of total stenosis and lumbar lordosis but, considering the data in each subgroup, the surgical techniques now can be planned tailored for each of them: the increase in the pelvic tilt should be corrected only in the subgroup of radiculopathy and the reduction in the offset in T9 should be treated only in the subgroup of claudication.

\section{CONCLUSION}

This study shows that there are significant correlations between symptoms and sagittal axis parameters between patients with and without spinal canal stenosis and also in subgroups of the patients with stenosis with different complaints, and these can be useful in clinical practice. New studies on the relationship between the symptoms and diseases of lumbar spine, with larger samples, are necessary for better diagnostic evaluation and therapy planning. 


\section{REFERENCES}

1. Berthonnaud E, Dimnet J, Roussouly P, Labelle H. Analysis of the sagittal balance of the spine and pelvis using shape and orientation parameters. J Spinal Disord Tech. 2005;18(1):40-7.

2. During J, Goudfrooij H, Keessen W, Beeker TW, Crowe A. Toward standards for posture. Postural characteristics of the lower back system in normal and pathologic conditions. Spine (Phila Pa 1976). 1985;10(1):83-7.

3. Glassman SD, Berven S, Bridwell K, Horton W, Dimar JR. Correlation of radiographic parameters and clinical symptoms in adult scoliosis. Spine (Phila Pa 1976). 2005:30(6):682-8.

4. Izumi Y, Kumano K. Analysis of sagittal lumbar alignment before and after posterior instrumentation: risk factor for adjacent unfused segment. Eur J Orthop Surg Traumatol. 2001;11(1):9-13. Available from: http://www.springerlink.com/content/q16h14h28xI06pv5/. Acessed in 2012 (may 21).

5. Korovessis P, Dimas A, lliopoulos P, Lambiris E. Correlative analysis of lateral vertebral radiographic variables and medical outcomes study short-form health survey: a comparative study in asymptomatic volunteers versus patients with low back pain. J Spinal Disord Tech. 2002;15(5):384-90.

6. Lazennec JY, Ramaré S, Arafati N, Laudet CG, Gorin M, Roger B, et al. Sagittal alignment in lumbosacral fusion: relations between radiological parameters and pain. Eur Spine J. 2000:9(1):47-55.

7. Vaz G, Roussouly P, Berthonnaud E, Dimnet J. Sagittal morphology and equilibrium of pelvis and spine. Eur Spine J. 2002;11(1):80-7.

8. Duval-Beaupère $\mathrm{G}$, Legaye J. Composante saggitale de la statique rachidienne. Rev Rhum. 2004;71:105-19. Available from: http://www.em-consulte.com/article/24130/article/composante-sagittale-de-la-statique-rachidienne. Acessed in 2012 (may 21).

9. Gautier J, Morillon P, Marcelli C. Does spinal morphology influence the occurrence of low back pain? A retrospective clinical, anthropometric, and radiological study. Rev Rhum Engl Ed. 1999;66(1):29-34.

10. Gelb DE, Lenke LG, Bridwell KH, Blanke K, McEnery KW. An analysis of sagittal alignment in 100 asymptomatic middle and older aged volunteers. Spine (Phila Pa 1976) 1995;20(12):1351-8

11. Ohtori S, Ito T, Yamashita M, Murata Y, Morinaga T, Hirayama J, et al. Evaluation of low back pain using the Japanese Orthopaedic Association Back Pain Evaluation Questionnaire for lumbar spinal disease in a multicenter study: differences in scores based on age, sex, and type of disease. J Orthop Sci. 2010;15(1):86-91.

12. Mangione P, Sénégas J. L'équilibre rachidien dans le plan sagittal. Rev Chir Orthop Traumatol. 1997;83(1):22-32. Available from: http://www.em-consulte.com/en/article/139714\#N10022. Accessed in 2012 (may 21).

13. Aebi M. Sagittal balance of spine: consequences for the treatment of the degenerative spine. Eur Spine J. 2011;20(Suppl 5):555.

14. Saal JS. General principles of diagnostic testing as related to painful lumbar spine disorders: a critical appraisal of current diagnostic techniques. Spine (Phila Pa 1976) 2002;27(22):2538-45.

15. Lund T. Reviewer's comment on "Sagittal balance of 85 patients with a lumbar degenerative disease: a comparative study" (by Cédric Y. Barrey et al.), (ESJ-05-0488.R2). Eur Spine J. 2007;16(9):1469-70.

16. Chaléat-Valayer E, Mac-Thiong JM, Paquet J, Berthonnaud E, Siani F, Roussouly P. Sagittal spino-pelvic alignment in chronic low back pain. Eur Spine J. 2011;20(Suppl 5):634-40.

17. George SZ, Hicks GE, Nevitt MA, Cauley JA, Vogt MT. The relationship between lumbar lordosis and radiologic variables and lumbar lordosis and clinical variables in elderly, African-American women. J Spinal Disord Tech. 2003;16(2):200-6.

18. Barrey C, Jund J, Noseda O, Roussouly P. Sagittal balance of the pelvis-spine complex and lumbar degenerative diseases. A comparative study about 85 cases. Eur Spine J. 2007;16(9):1459-67.

19. Vital JM, Gille O, Gangnet N. Équilibre sagittal et applications cliniques. Rev Rhum. 2004;71(2):120-8. Available from: http://www.em-consulte.com/article/24131/article/ equilibre-sagittal-et-applications-cliniques. Accessed in 2012 (may 21).

20. Roussouly P, Gollogly S, Berthonnaud E, Dimnet J. Classification of the normal variation in the sagittal alignment of the human lumbar spine and pelvis in the standing position. Spine (Phila Pa 1976). 2005;30(3):346-53.

21. Rajnics $P$, Temphier A, Skalli W, Lavaste F, Illes T. The importance of spinopelvic parameters in patients with lumbar disc lesions. Int Orthop. 2002;26(2):104-8.

22. Janssen MM, Drevelle $X$, Humbert L, Skalli W, Castelein RM. Differences in male and female spino-pelvic alignment in asymptomatic young adults: a three-dimensional analysis using upright low-dose digital biplanar X-rays. Spine (Phila Pa 1976). 2009;34(23):E826-32.

23. Geiger EV, Müller O, Niemeyer T, Kluba T. Adjustment of pelvispinal parameters preserves the constant gravity line position. Int Orthop. 2007;31(2):253-8.

24. Kobayashi T, Atsuta Y, Matsuno T, Takeda N. A longitudinal study of congruent sagittal spinal alignment in an adult cohort. Spine (Phila Pa 1976). 2004;29(6):671-6.

25. Kirkwood BR, Sterne JAC. Essential medical statistics. 2nd ed. Massachusetts: Blackwell Science; 2003.

26. Boulay C, Tardieu C, Hecquet J, Benaim C, Mouilleseaux B, Marty C, et al. Sagittal alignment of spine and pelvis regulated by pelvic incidence: standard values and prediction of lordosis. Eur Spine J. 2006:15(4):415-22.

27. Suzuki H, Endo K, Mizuochi J, Kobayashi H, Tanaka H, Yamamoto K. Clasped position for measurement of sagittal spinal alignment. Eur Spine J. 2010;19(5):782-6. 